\title{
The effects of naltrexone among alcohol non-abstainers: results from the COMBINE Study
}

\author{
Lara A. Ray ${ }^{1}{ }^{*}$, Jennifer L. Krull' ${ }^{1}$ and Lorenzo Leggio ${ }^{2}$ \\ 1 Department of Psychology, University of California at Los Angeles, Los Angeles, CA, USA \\ 2 Center for Alcohol and Addiction Studies, Brown University, Providence, RI, USA
}

Edited by:

Paul S. Haber, University of Sydney,

Australia

Reviewed by:

Kirsten Morley, The University of

Sydney, Australia

Raymond Anton, The Medical

University of South Carolina, USA

\section{${ }^{*}$ Correspondence:}

Lara A. Ray, Department of Psychology,

Brain Research Institute, University of

California at Los Angeles, 1285 Franz

Hall, Box 951563, Los Angeles, CA

90095-1563, USA.

e-mail: lararay@psych.ucla.edu
These analyses of the COMBINE Study examined the effects of naltrexone among nonabstainers. Given that one of the most well-established mechanisms of action of naltrexone involves blunting of alcohol reward, it is hypothesized that naltrexone should be more effective among individuals who drank during treatment. Participants were 952 (78\% of the total COMBINE Study sample) treatment-seeking alcohol-dependent men and women who received pharmacotherapy for alcoholism and drank at least once during the 16-week trial. Mixed model analyses revealed that individuals who drank more regularly during the trial seemed to benefit most from naltrexone and the effects of naltrexone on heavy drinking was significant in treatment months 2 through 4 among individuals who reported drinking on 81,68 , and $60 \%$ or more of days, respectively. Those drinking frequencies were observed in 11,15 , and $19 \%$ of the sample. Similar effects were not observed for drinks per drinking day. These results suggest that a small subgroup of non-abstainers, composed primarily of very regular drinkers, appears to benefit from naltrexone in reducing heavy drinking days. Naltrexone may be effective in the context of controlled-drinking approaches, even among very frequent drinkers.

Keywords: COMBINE Study, naltrexone, heavy drinking, alcoholism, abstainer

\section{INTRODUCTION}

Naltrexone is an opioid receptor antagonist with empirically supported efficacy for the treatment of alcoholism when used in combination with behavioral treatments (e.g., O'Malley et al., 1992; Volpicelli et al., 1992; Anton et al., 1999, 2006; Monti et al., 2001). Shortly after two initial trials suggested that naltrexone resulted in significantly fewer drinking days and lower rates of relapse after 3 months of treatment (O'Malley et al., 1992; Volpicelli et al., 1992), naltrexone was advanced as one of the more promising pharmacological interventions for alcohol dependence (Litten et al., 1996). These initial results have been largely supported by more recent trials of naltrexone that generally demonstrate beneficial effects on heavy drinking rates (Anton et al., 1999; Chick et al., 2000; Monti et al., 2001; Morris et al., 2001).

Clinical trials have found that naltrexone reduces the occurrence of heavy drinking days (Monti et al., 2001; Rubio et al., 2002; Balldin et al., 2003), increases time to first relapse (Anton et al., 1999; Guardia et al., 2002; Kiefer et al., 2003), yields lower relapse rates (Volpicelli et al., 1992; Heinala et al., 2001; Latt et al., 2002), reduces the number of drinking days (O'Malley et al., 1992; Volpicelli et al., 1992), the number of drinks per drinking episode (O'Malley et al., 1992; Chick et al., 2000; Morris et al., 2001; Guardia et al., 2002), and the latency to first and second drink among social drinkers (Davidson et al., 1996). However, the support for naltrexone is not uniform. A few trials, including a large multi-site trial, have reported no significant outcome differences between naltrexone and placebo-treated patients (Kranzler et al., 2000; Krystal et al., 2001). Recent trajectory-based re-analyses of two negative clinical trials suggested that naltrexone may have a clinically meaningful effect in decreasing the risk of consistent heavy drinking and increasing the likelihood of abstinence from alcohol in those studies (Gueorguieva et al., 2007).

In addition to determining the efficacy of naltrexone for the treatment of alcoholism, research has focused on understanding the biobehavioral mechanisms and moderators of response to naltrexone. To that end, human laboratory studies revealed that naltrexone dampens alcohol's positively reinforcing effects (Swift et al., 1994; McCaul et al., 2001; Drobes et al., 2004; Ray and Hutchison, 2007), attenuates alcohol craving (O'Malley et al., 2002; Ray and Hutchison, 2007; Tidey et al., 2008), reduces alcohol self-administration (O'Malley et al., 2002; Anton et al., 2004), decreases ratings of liking of the alcohol (McCaul et al., 2000; Ray and Hutchison, 2007), increases alcohol-induced feelings of fatigue, tension, and confusion (King et al., 1997), reduces alcohol consumption and slows down the progression of drinking in a delayed access laboratory paradigm (Anton et al., 2004). In short, these results suggest that one of the primary biobehavioral mechanisms of action of naltrexone involves the reduction of alcohol-induced reward, which by definition, presumes alcohol consumption by patients while treated with naltrexone.

Studies of the neurobiological effects of naltrexone revealed that it occupies opioid receptors preventing the binding of such receptors by endogenous opioid peptides released upon alcohol intake. This in turn prevents the $\gamma$-aminobutyric acid (GABA)-mediated release of dopamine in the ventral tegmental areas thereby putatively blocking alcohol's reinforcing effects (Anton et al., 1995; Koob and Le Moal, 2008). A neuroimaging study found that naltrexone reduces alcohol-mediated dopamine output in the ventral striatum (Myrick et al., 2008). Opioid peptides may also play a role in 
alcohol and drug reward through non-dopamine mediated pathways (Koob, 1992). Opioid blockade, tested mostly using naloxone, has been found to increase blood levels of adrenocorticotropic hormone $(\mathrm{ACTH})$, beta-endorphin, and cortisol in humans (Naber et al., 1981; Schluger et al., 1998). Nevertheless, null findings have also been reported (Kemper et al., 1990). These findings suggest a potential role of the hypothalamo-pituitary-adrenocortical (HPA) axis activity in mediating the neurobiological effects of naltrexone, a finding that is supported by recent human laboratory studies (e.g., O'Malley et al., 2002; Ray et al., 2009). As with the biobehavioral mechanisms reviewed above, the putative neurobiological mechanisms of naltrexone involve the blunting of alcohol-induced reward through both opioid and dopamine mediated pathways.

The COMBINE Study was a large multi-site 16-week alcohol dependence treatment study (see Materials and Methods for details). The main results from the COMBINE Study indicated that naltrexone was superior to no-naltrexone on a number of drinking outcome variables. The effects of naltrexone were in large part observable only when behavioral counseling (i.e., Combined Behavioral Intervention, CBI) was not used concomitantly with naltrexone and Medical Management (MM). Details on the main results of the COMBINE study have been described in Anton et al. (2006). In light of the literature on the biobehavioral and neurobiological mechanisms of action of naltrexone, these secondary analyses of the COMBINE Study (2003a,b) seek to examine the effects of naltrexone among individuals who drank during the course of the 16-week treatment. Given that one of the most well-established mechanisms of action of naltrexone involves blunting of alcohol reward, it is hypothesized that naltrexone should be effective among individuals who drank during the COMBINE trial.

Specifically, we hypothesize that the degree to which patients drink during the trial may moderate the efficacy of naltrexone, as measured by the following outcomes: (a) percent heavy drinking days (PHDD) and (b) drinks per drinking day (DPDD). This is consistent with the recognition that, at least some, of the well-established mechanisms of action of naltrexone presuppose alcohol consumption. Alcohol is thought to interact with the pharmacological effects of naltrexone resulting in decreased reinforcing effects from alcohol and ultimately, reduced alcohol intake within a drinking episode (Pettinati et al., 2006). An examination of outcomes among individuals who drank during treatment in the COMBINE Study (i.e., non-abstainers) and of the frequency with which they drank is consistent with the putative mechanisms of naltrexone action that involve changes in subjective intoxication. These biobehavioral mechanisms, in turn, are often captured in human laboratory studies and these analyses will bridge the human behavioral pharmacology and clinical treatment approaches. These analyses will also provide clinically useful information on treatment non-abstainers, including their response to naltrexone and how drinking frequency influences drinking outcomes and naltrexone response.

\section{MATERIALS AND METHODS}

\section{SUMMARY OF THE COMBINE STUDY}

The rationale and methods of the COMBINE Study (2003a,b) have been described in detail elsewhere. In brief, COMBINE was designed to test the outcome of different levels of pharmacotherapy and psychotherapy interventions for alcoholism. A total of
1383 participants were recruited at 11 U.S. sites, all of whom were outpatients who met criteria for alcohol dependence and who had been drinking heavily for the 90 -day period preceding study enrollment (i.e., at least two heavy drinking days - defined as four drinks per day for women and five drinks per day for men, during a consecutive 30 -day period within the 90 days prior to baseline evaluation). Exclusion criteria were any serious mental illness or unstable medical condition, current dependence on any drug other than alcohol, nicotine, or marijuana, taking or requiring any medication that interfered with the study medications, including any significant current opioid use.

Participants were randomly assigned to one of nine treatment conditions and received 16 weeks of active treatment. Eight of these groups $(n=1226)$ received MM plus a combination of either active/placebo naltrexone and active/placebo acamprosate. These four medication groups were then further divided by two levels of behavioral counseling (i.e., CBI vs. no CBI). A ninth group $(n=157)$ received CBI alone, without MM or pills and will not be included in the analyses presented herein given the focus on naltrexone response. Naltrexone dose in the COMBINE trial was $100 \mathrm{mg} /$ day (after a 7-day titration up). The primary outcomes for the trial were percent days abstinent and time to first heavy drinking day, operationalized as five or more drinks in a day for men and four or more drinks in a day for women.

\section{DATA ANALYTIC STRATEGY}

Outcome variables and covariates were culled from the COMBINE database. The Form 90 (Miller and Del Boca, 1994; Tonigan et al., 1997) was the primary measure of drinking outcomes. This instrument was administered at 4-week intervals over the course of 16 weeks. Consistent with the study hypotheses, the outcome variables for these analyses were: (a) PHDD and (b) DPDD. In theses analyses, we excluded individuals who remained abstinent during the 16-week trial ( $n=274,22 \%)$, leaving a total of 952 participants who drank at least once during the trial. In order to examine the effects of naltrexone on PHDD and DPDD, a series of repeated measures mixed model analyses were conducted using PROC MIXED in SAS Statistical Software. Grouping of the medication and psychosocial treatment conditions were identical to those in the Analyses of Variance (ANOVAs) conducted for the main trial (Anton et al., 2006).

Consistent with the approach of the primary analyses of the COMBINE Study (Anton et al., 2006) the effects of naltrexone were examined across levels of behavioral counseling and acamprosate, in order to maximize statistical power. Given that the present study focuses on the effects of naltrexone among non-abstainers, levels of counseling were not added to the statistical models. In these analyses, each dependent variable (PHDD and DPDD) was modeled as a function of time (linear and quadratic effects of month, initially centered at the 1 -month assessment), naltrexone ( $0=$ no, $1=$ yes $)$, and percent drinking days (PDD, modeled with both linear and quadratic effects), and their interactions. The interaction between $\mathrm{PDD}$, a time varying covariate capturing drinking frequency, and naltrexone allowed us to test whether the efficacy of naltrexone vs. no-naltrexone on drinking outcomes differed as a function of drinking levels over the course of treatment. The intercept and time trends were allowed to vary randomly across individuals. 
Non-significant interactions were trimmed from the final models reported below. All analyses controlled for pre-treatment levels of the relevant dependent measure. Lastly, a Bonferroni correction was implemented and since two dependent variables were analyzed in this study, the adjusted critical $p$-value was set at 0.025 . This is the same $a$ priori adjusted $p$-value used in the COMBINE Study main analyses (Anton et al., 2006).

\section{RESULTS}

Correlational analyses examined the associations between the three measures of drinking used in this study: (a) PDD; (b) PHDD; and (c) DPDD. Across the 4 months of active treatment, the association between PDD and DPDD ranged between $r=0.08$ and 0.18 . The association between PDD and PHDD ranged between $r=0.78$ and 0.81 . And the correlation between DPDD and PHDD ranged between $r=0.42$ and 0.49 . The following analyses address the primary study objectives.

\section{PERCENT HEAVY DRINKING DAYS}

As shown in Table 1, mixed model analyses revealed a number of significant higher-order interactions, including a significant Month $\times$ drinking frequency $(\mathrm{PDD}) \times$ Naltrexone interaction $[B=-0.03, \mathrm{SE}=0.01, t(2731)=-2.86, p<0.01]$ and a significant quadratic $\mathrm{PDD} \times$ Naltrexone interaction $[B=-0.002, \mathrm{SE}=0.0005$, $t(2731)=-3.75, p<0.01]$. This indicates a complex pattern in the benefit of Naltrexone treatment for individuals with varying frequency of alcohol use over time (see Figure 1). There was no significant difference between naltrexone and no-naltrexone at month 1 . Successively re-centering the time and PDD variables and rerunning the analyses allowed us to determine which individuals (as a function of their drinking pattern) experienced a benefit from

Table 1 | Parameter estimates and standard errors from trimmed multilevel growth models of percent heavy drinking days (PHDD) and drinks per drinking day (DPDD) outcome variables.

\begin{tabular}{|c|c|c|c|c|}
\hline \multirow[t]{2}{*}{ Variable } & \multicolumn{2}{|c|}{ PHDD } & \multicolumn{2}{|c|}{ DPDD } \\
\hline & $\begin{array}{l}\text { Parameter } \\
\text { estimate }\end{array}$ & $\begin{array}{l}\text { Standard } \\
\text { error }\end{array}$ & $\begin{array}{l}\text { Parameter } \\
\text { estimate }\end{array}$ & $\begin{array}{l}\text { Standard } \\
\text { error }\end{array}$ \\
\hline Intercept & $-4.48 * *$ & 1.39 & $1.36 * * *$ & 0.37 \\
\hline NTX & $-2.41^{\dagger}$ & 1.25 & -0.43 & 0.27 \\
\hline NTX $\times$ month & 0.37 & 0.48 & - & - \\
\hline PDD & $0.49 * * *$ & 0.04 & $0.06 * * *$ & 0.01 \\
\hline PDD $\times$ month & $0.05^{*}$ & 0.02 & $-0.01^{\dagger}$ & 0.007 \\
\hline PDD $\times$ month $\times$ month & $-0.02 * * *$ & 0.01 & - & - \\
\hline PDD $\times$ PDD & $0.002^{* * *}$ & 0.001 & $-0.0004^{* *}$ & 0.0001 \\
\hline PDD $\times$ PDD $\times$ month & $0.001^{*}$ & 0.0002 & $0.0002^{\dagger}$ & 0.00007 \\
\hline NTX $\times$ PDD & $0.19 * * *$ & 0.05 & 0.006 & 0.006 \\
\hline NTX $\times$ PDD $\times$ month & $-0.03 * *$ & 0.01 & - & - \\
\hline $\mathrm{NTX} \times \mathrm{PDD} \times \mathrm{PDD}$ & $-0.002 * * *$ & 0.001 & - & - \\
\hline Month & -0.81 & 0.68 & $0.69 * * *$ & 0.19 \\
\hline Month $\times$ month & 0.26 & 0.20 & $-0.17 * * *$ & 0.05 \\
\hline Baseline measure & $0.07^{* * *}$ & 0.02 & $0.37 * * *$ & 0.02 \\
\hline
\end{tabular}

${ }^{t} p<0.10,{ }^{*} p<0.025,{ }^{* *} p<0.01,{ }^{* * *} p<0.001$.

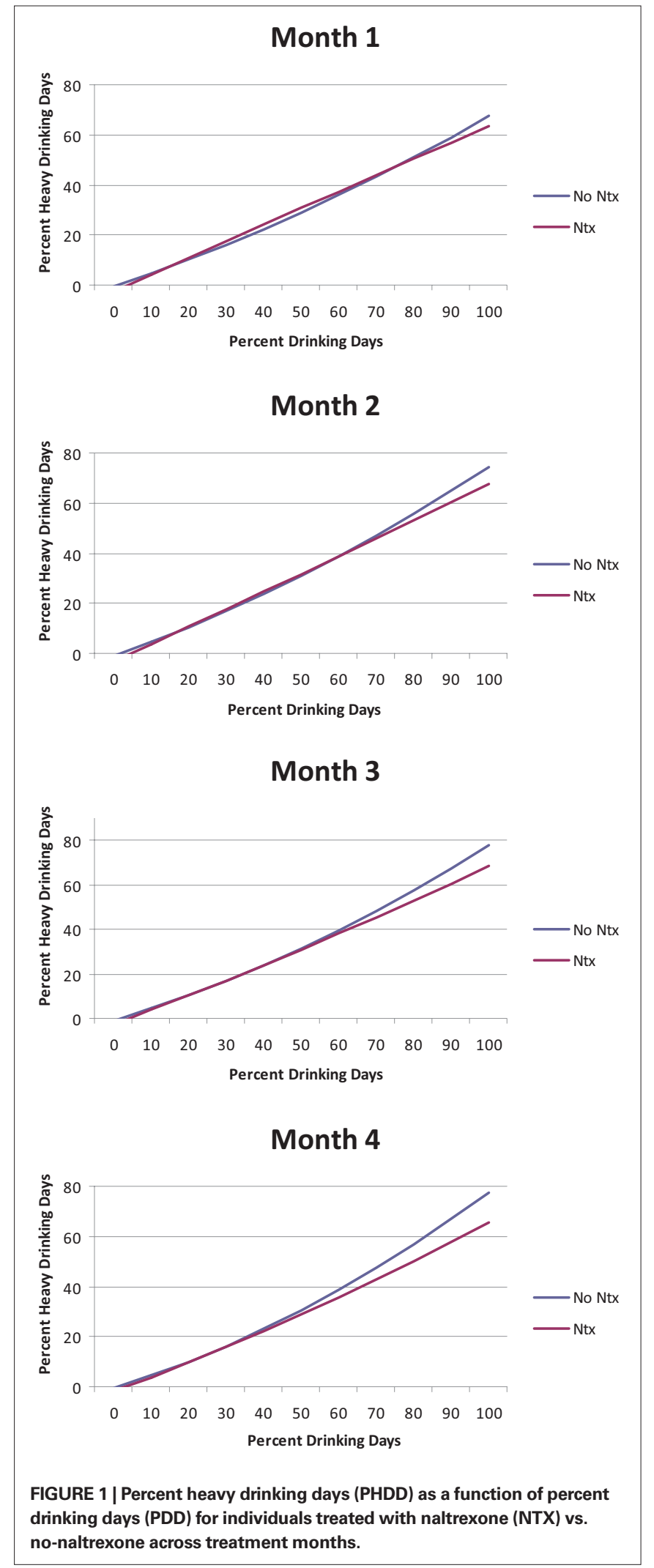

naltrexone during the later course of treatment. Specifically, there was no significant difference between naltrexone and no-naltrexone treatment on PHDD, across levels of drinking frequency (PDD) 
at month 1 . At month 2, however, naltrexone became statistically superior to no-naltrexone in reducing heavy drinking days among individuals who reported $80 \%$ or more drinking days, which in turn represents $11 \%$ of participants in these analyses. At month 3, naltrexone significantly reduced PHDD among individuals who drank on approximately two-thirds of days or more (i.e., $\geq 68 \%$ drinking days), which represents $15 \%$ of the participants in these analyses. And finally, at month 4, naltrexone was superior to no-naltrexone in reducing PHDD among individuals who reported $60 \%$ or more drinking days, which was the case for $19 \%$ of the sample. This pattern indicates that over time, the effects of naltrexone became significant at lower drinking frequency.

In summary, the effects of naltrexone on PHDD among nonabstainers were moderated by drinking frequency, such that higher frequency of drinking was associated with greater benefit from naltrexone, as compared to no-naltrexone. The benefits of naltrexone were not significant at treatment month 1, but became statistically significant at different levels of drinking frequency across treatment months 2,3, and 4 . These findings suggest that a small subgroup of non-abstainers (11-19\% of the sample) benefits from naltrexone in reducing heavy drinking days.

\section{DRINKS PER DRINKING DAY}

Mixed model analysis revealed no significant drinking frequency $(\mathrm{PDD}) \times$ naltrexone interaction $[B=0.005, \mathrm{SE}=0.006$, $t(2043)=0.89, p=0.37]$ with regard to DPDD. Moreover, there were no significant higher-order interactions involving this effect.

\section{DISCUSSION}

This study examined the clinical effects of naltrexone among individuals who drank over the course of treatment in the COMBINE Study. Given the putative mechanisms of action of this pharmacotherapy, namely its reduction of alcohol "high" (Swift et al., 1994; Volpicelli et al., 1995), it was hypothesized that the degree to which patients drink during the trial would moderate the efficacy of naltrexone. Specifically, it was argued that regular drinking in the presence of active naltrexone treatment would lead to clinical benefits, such as reductions in heavy drinking days and DPDD via naltrexone-induced alteration of the neuropharmacological effects of alcohol. Results of these analyses, excluding all abstainers from the COMBINE Study, provided partial support for these hypotheses such that naltrexone interacted with PDD in predicting PHDD following the grace period of 1 month (i.e., re-centering the treatment variable). Among non-abstainers, which represents the vast majority (78\%) of patients in the COMBINE Study, individuals who drank more regularly during the trial seemed to benefit most from naltrexone and the difference between naltrexone and non-naltrexone on PHDD was significant in treatment months 2 through 4 among individuals who drank on 81,68 , and $60 \%$ or more of days. Similar effects, however, were not observed for DPDD. Taken together, these results are somewhat consistent with the putative mechanism of action of naltrexone and suggest that naltrexone's beneficial effects among non-abstainers may depend on frequency of drinking.

Importantly, the percentage of non-abstainers found to benefit from naltrexone in reducing heavy drinking was at best 20\%. Albeit small, these numbers are consistent with meta-analytic findings suggesting a small effect size of naltrexone for alcoholism treatment and arguing that naltrexone may be most useful in the context of controlled drinking (Bouza et al., 2004).These findings may also be interpreted in light of studies suggesting that naltrexone may be most effective among patients with low levels of alcohol dependence severity (Morley et al., 2006). To the extent to which individuals who drank during treatment in the COMBINE study had lower levels of alcohol dependence severity and were more prone to a controlled-drinking treatment goal, it is possible that alcoholism severity may help explain these findings. This is consistent with the observation that a low severity of alcohol dependence in the COMBINE sample may explain, at least partially, some divergent results between trials in Europe and the US (e.g., alcohol dependence score of 38.6 in a recent German trial vs. 16.6 in the US COMBINE trial) (Mann et al., 2007).

Interestingly, the significant reduction over time in the percentage of drinking days per month required to observe an effect of naltrexone on heavy drinking may be seen as consistent with the learning theory of addiction, suggesting that repeated experience of alcohol use at lower levels of reinforcement, putatively due to naltrexone's effects, may be required to modify drinking behavior (i.e., produce reductions in PHDD). The lack of significant effects at the first month of treatment may also be interpreted from the perspective of a "grace period" in the trial, during which the full potential of a treatment is not yet observable. Although we did not use a "grace period" approach in these analyses, FDA recommendations suggest that a grace period may be used in a trial to allow the medication to reach therapeutic levels, and importantly, to allow patients to adjust to the medication regimen and begin to control their drinking with the behavioral and pharmacological tools (FDA, 2006). Although the current study was not aimed at identifying the optimal therapeutic window for naltrexone, these findings may have important clinical implications. Specifically, these results suggest that patients who drinking regularly should be encouraged to use naltrexone for at least 1 month before medication gains can be objectively evaluated.

These results are generally consistent with the clinical observation and previous empirical studies suggesting that naltrexone may work, in part, by preventing drinking episodes from becoming a full-fledge relapse into heavy drinking (Anton et al., 1999, 2004; O'Malley and Froehlich, 2003; Pettinati et al., 2006). The present study addresses the relationship between naltrexone and drinking outcomes thought to result from naltrexone-induced blunting of alcohol reinforcement, which by definition involves alcohol use by naltrexone-treated patients. Conversely, this study does not address the effects of naltrexone in promoting abstinence, which has also been reported in the literature (Volpicelli et al., 1992; Heinala et al., 2001; Latt et al., 2002). Naltrexone's effects on abstinence rates, in turn, may be attributed to alternative mechanisms of action of this pharmacotherapy, such as reductions in alcohol craving (Anton et al., 1999; Monti et al., 2001; Tidey et al., 2008) and improvements in response inhibition and more generally, in executive function (Crews and Boettiger, 2009).

These results presented herein should be interpreted in the context of the study's strengths and limitations. Strengths include the large and well-characterized sample as well as the methodological 
rigor of the COMBINE Study. These results provide an indirect test of a putative mechanism of action of naltrexone (i.e., blunting of alcohol-induced reinforcement) in a treatment setting, which affords a more naturalistic drinking context (i.e., amount of patients' drinking across 16 weeks of treatment), and in a treatment-seeking sample of patients with a current DSM-IV diagnosis of alcohol dependence. To date, mechanisms of action of naltrexone have been often captured in human laboratory settings, with non-treatment-seeking samples, who at times do not meet diagnostic criteria for alcohol dependence. Limitations include the use of a dependent measure of drinking (i.e., PDD) to predict other drinking outcomes (i.e., PHDD and DPDD). Although collinearity between these measures may be problematic, the use of advanced quantitative approaches, consistent with those employed in the main results from this trial (Anton et al., 2006) serves to ensure that these findings reflect quantitative, as well as potentially clinically meaningful, indices of the effects of naltrexone on drinking outcomes among non-abstainers in this trial. The results of this study are limited to individuals who selfselected into the non-abstainer category over the course of treatment. Future studies employing novel quantitative methods, such as semi-parametric regressions (Zhou and Liang, 2006), to the study of treatment outcome for alcoholism are clearly warranted in light of the complexity and non-linear nature of the recovery phenomenon (Witkiewitz, 2008).

\section{REFERENCES}

Anton, R. F., Drobes, D. J., Voronin, K., Durazo-Avizu, R., and Moak, D. (2004). Naltrexone effects on alcohol consumption in a clinical laboratory paradigm: temporal effects of drinking. Psychopharmacology (Berl.) 173, 32-40.

Anton, R. F., Kranzler, H. R., and Meyer, R.E. (1995). Neurobehavioral aspects of the pharmacotherapy of alcohol dependence. Clin. Neurosci. 3, 145-154.

Anton, R. F., Moak, D. H., Waid, L. R., Latham, P. K., Malcolm, R. J., and Dias, J. K. (1999). Naltrexone and cognitive behavioral therapy for the treatment of outpatient alcoholics: results of a placebo-controlled trial. Am. J. Psychiatry 156, 1758-1764.

Anton, R. F., O’Malley, S. S., Ciraulo, D. A., Cisler, R. A., Couper, D., Donovan, D. M., Gastfriend, D. R., Hosking, J. D., Johnson, B. A., LoCastro, J. S., Longabaugh, R., Mason, B. J., Mattson, M. E., Miller, W. R., Pettinati, H. M., Randall, C. L., Swift, R., Weiss, R. D., Williams, L. D., and Zweben,A. (2006). Combined pharmacotherapies and behavioral interventions for alcohol dependence: the COMBINE study: a randomized controlled trial. JAMA 295, 2003-2017.

Anton, R. F., Oroszi, G., O’Malley, S., Couper, D., Swift, R., Pettinati, H., and Goldman, D. (2008). An (OPRM1) as a predictor of naltrex-

In summary, these analyses of the COMBINE Study complement and extend the study's main findings by examining the effects of naltrexone among individuals who drank during treatment, who in turn represent the vast majority (78\%) of COMBINE Study participants, and by leveraging advanced quantitative models of behavior change. The findings make a unique contribution by demonstrating that a subgroup of non-abstainers, composed primarily of very regular drinkers, appears to benefit from naltrexone in reducing heavy drinking days. Several issues remain to be addressed in efforts to optimize the use of this pharmacotherapy for alcoholism, such as the pharmacogenetics of naltrexone (Oslin et al., 2003; Ray and Hutchison, 2007; Anton et al., 2008; O’Brien, 2008), medication compliance (Zweben et al., 2008), treatment persistence (Kranzler et al., 2008), and psychiatric comorbidity (Petrakis et al., 2004; Pettinati et al., 2010). Ultimately, the optimization of naltrexone for alcohol dependence hinges upon the integration of these lines of research into clinical prescriptions and protocols that support behavior change and recovery from alcoholism.

\section{ACKNOWLEDGMENTS}

Data presented in this report were collected as part of the multi-site COMBINE trial sponsored by the National Institute on Alcohol Abuse and Alcoholism (NIAAA), in collaboration with the Combine Study Research Group. A full listing of COMBINE study staff can be found at http://www.cscc.unc.edu/combine/

study. Alcohol. Clin. Exp. Res. 27, 1123-1131.

evaluation of mu-opioid receptor one response in the treatment of alcohol dependence: results from the Combined Pharmacotherapies and Behavioral Interventions for Alcohol Dependence (COMBINE) study. Arch. Gen. Psychiatry 65, 135-144.

Balldin, J., Berglund, M., Borg, S., Mansson, M., Bendtsen, P., Franck, J., Gustafsson, L., Halldin, J., Nilsson, L. H., Stolt, G., and Willander, A. (2003). A 6-month controlled naltrexone study: combined effect with cognitive behavioral therapy in outpatient treatment of alcohol dependence. Alcohol. Clin. Exp. Res. 27, 1142-1149.

Bouza, C., Angeles, M., Munoz, A., and Amate, J. M. (2004). Efficacy and safety of naltrexone and acamprosate in the treatment of alcohol dependence: a systematic review. Addiction 99, 811-828.

Chick, J., Anton, R., Checinski, K., Croop, R., Drummond, D. C., Farmer, R., Labriola, D., Marshall, J., Moncrieff, J., Morgan, M.Y., Peters, T., and Ritson, B. (2000). A multicentre, randomized, double-blind, placebo-controlled trial of naltrexone in the treatment of alcohol dependence or abuse. Alcohol Alcohol. 35, 587-593.

COMBINE Study. (2003a). Testing combined pharmacotherapies and behavioral interventions for alcohol dependence: a pilot feasibility
COMBINE Study. (2003b). Testing combined pharmacotherapies and behavioral interventions in alcohol dependence: rationale and methods. Alcohol. Clin. Exp. Res. 27, 1107-1122.

Crews, F. T., and Boettiger, C. A. (2009) Impulsivity, frontal lobes and risk for addiction. Pharmacol Biochem Behav. 93, 237-247.

Davidson, D., Swift, R., and Fitz, E. (1996). Naltrexone increases the latency to drink alcohol in social drinkers. Alcohol. Clin. Exp. Res. 20, 732-739.

Drobes, D. J., Anton, R. F., Thomas, S. E., and Voronin, K. (2004). Effects of naltrexone and nalmefene on subjective response to alcohol among nontreatment-seeking alcoholics and social drinkers. Alcohol. Clin. Exp. Res. 28, 1362-1370.

FDA. (2006). Medical Review of Vivitrol. Rockville, MD: Government, U.S.

Guardia, J., Caso, C., Arias, F., Gual, A., Sanahuja, J., Ramirez, M., Mengual, I., Gonzalvo, B., Segura, L., Trujols, J., and Casas, M. (2002). A doubleblind, placebo-controlled study of naltrexone in the treatment of alcoholdependence disorder: results from a multicenter clinical trial. Alcohol. Clin. Exp. Res. 26, 1381-1387.

Gueorguieva, R., Wu, R., Pittman, B., Cramer, J., Rosenheck, R. A., O’Malley
S, S., and Krystal, J. H. (2007). New insights into the efficacy of naltrexone based on trajectory-based reanalyses of two negative clinical trials. Biol. Psychiatry 61, 1290-1295.

Heinala, P., Alho, H., Kiianmaa, K., Lonnqvist, J., Kuoppasalmi, K., and Sinclair, J. D. (2001). Targeted use of naltrexone without prior detoxification in the treatment of alcohol dependence: a factorial double-blind, placebo-controlled trial. J. Clin. Psychopharmacol. 21, 287-292.

Kemper, A., Koalick, F., Thiele, H., Retzow, A., Rathsack, R., and Nickel, B. (1990). Cortisol and betaendorphin response in alcoholics and alcohol abusers following a high naloxone dosage. Drug Alcohol Depend. 25, 319-326.

Kiefer, F., Jahn, H., Tarnaske, T., Helwig, H., Briken, P., Holzbach, R., Kampf, P., Stracke, R., Baehr, M., Naber, D., and Wiedemann, K. (2003). Comparing and combining naltrexone and acamprosate in relapse prevention of alcoholism: a double-blind, placebocontrolled study. Arch. Gen. Psychiatry 60, 92-99.

King, A. C., Volpicelli, J. R., Frazer, A., and O'Brien, C. P. (1997). Effect of naltrexone on subjective alcohol response in subjects at high and low risk for future alcohol dependence. Psychopharmacology (Berl.) 129, 15-22. 
Koob, G. F. (1992). Drugs of abuse: anatomy, pharmacology and function of reward pathways. Trends Pharmacol. Sci. 13, 177-184.

Koob, G. F., and Le Moal, M. (2008). Addiction and the brain antireward system. Annu. Rev. Psychol. 59, 29-53.

Kranzler, H. R., Modesto-Lowe, V., and Van Kirk, J. (2000). Naltrexone vs. nefazodone for treatment of alcohol dependence. A placebo-controlled trial. Neuropsychopharmacology 22, 493-503.

Kranzler, H. R., Stephenson, J. J., Montejano, L., Wang, S., and Gastfriend, D. R. (2008). Persistence with oral naltrexone for alcohol treatment: implications for healthcare utilization. Addiction 103, 1801-1808.

Krystal, J. H., Cramer, J. A., Krol, W. F., Kirk, G. F., and Rosenheck, R. A. (2001). Naltrexone in the treatment of alcohol dependence. N. Engl. J. Med. 345, 1734-1739.

Latt, N. C., Jurd, S., Houseman, J., and Wutzke, S. E. (2002). Naltrexone in alcohol dependence: a randomised controlled trial of effectiveness in a standard clinical setting. Med. J. Aust. 176, 530-534.

Litten, R. Z., Allen, J., and Fertig, J. (1996). Pharmacotherapies for alcohol problems: a review of research with focus on developments since 1991. Alcohol. Clin. Exp. Res. 20, 859-876.

Mann, K., Anton, R., Kiefer, F., and Smolka, M. (2007). Are patients in the US treatment trials different from European patients? A comparison between the COMBINE Study and the Project PREDICT. Alcohol. Clin. Exp. Res. 31, 58A.

McCaul, M. E., Wand, G. S., Eissenberg, T., Rohde, C. A., and Cheskin, L. J. (2000). Naltrexone alters subjective and psychomotor responses to alcohol in heavy drinking subjects. Neuropsychopharmacology 22, 480-492.

McCaul, M. E., Wand, G. S., Stauffer, R., Lee, S. M., and Rohde, C. A. (2001). Naltrexone dampens ethanol-induced cardiovascular and hypothalamicpituitary-adrenal axis activation. Neuropsychopharmacology 25, 537-547.

Miller, W. R., and Del Boca, F. K. (1994). Measurement of drinking behavior using the Form 90 family of instruments. J. Stud. Alcohol Suppl. 12, 112-118.
Monti, P.M., Rohsenow, D. J., Swift, R. M., Gulliver, S. B., Colby, S. M., Mueller, T. I., Brown, R. A., Gordon, A., Abrams, D. B., Niaura, R. S., and Asher, M. K. (2001). Naltrexone and cue exposure with coping and communication skills training for alcoholics: treatment process and 1-year outcomes. Alcohol. Clin. Exp. Res. 25, 1634-1647.

Morley, K. C., Teesson, M., Reid, S. C., Sannibale, C., Thomson, C., Phung, N., Weltman, M., Bell, J. R., Richardson, K., and Haber,P.S.(2006). Naltrexoneversus acamprosate in the treatment of alcohol dependence:amulti-centre, randomized, double-blind, placebo-controlled trial. Addiction 101, 1451-1462.

Morris, P. L., Hopwood, M., Whelan, G., Gardiner, J., and Drummond, E. (2001). Naltrexone for alcohol dependence: a randomized controlled trial. Addiction 96, 1565-1573.

Myrick, H., Anton, R. F., Li, X., Henderson, S., Randall, P. K., and Voronin, K. (2008). Effect of naltrexone and ondansetron on alcohol cue-induced activation of the ventral striatum in alcohol-dependent people. Arch. Gen. Psychiatry 65, 466-475.

Naber, D., Pickar, D., Davis, G. C., Cohen, R. M., Jimerson, D. C., Elchisak, M.A., Defraites, E. G., Kalin, N. H., Risch, S. C., and Buchsbaum, M. S. (1981). Naloxone effects on beta-endorphin, cortisol, prolactin, growth hormone, HVA and MHPG in plasma of normal volunteers. Psychopharmacology (Berl.) 74, 125-128.

O’Brien, C. P. (2008). Prospects for a genomic approach to the treatment of alcoholism. Arch. Gen. Psychiatry 65, 132-133.

O'Malley, S. S., and Froehlich, J. C. (2003). Advances in the use of naltrexone: an integration of preclinical and clinical findings. Recent Dev. Alcohol. 16, 217-245.

O’Malley, S. S., Jaffe, A. J., Chang, G., Schottenfeld, R. S., Meyer, R. E., and Rounsaville, B. (1992). Naltrexone and coping skills therapy for alcohol dependence. A controlled study. Arch. Gen. Psychiatry 49, 881-887.

O’Malley, S. S., Krishnan-Sarin, S., Farren, C., Sinha, R., and Kreek, M. J. (2002). Naltrexone decreases craving and alcohol self-administration in alcoholdependent subjects and activates the hypothalamo-pituitary-adrenocortical axis. Psychopharmacology (Berl.) 160, 19-29.

Oslin, D.W., Berrettini, W., Kranzler, H. R., Pettinati,H., Gelernter,J., Volpicelli,J.R., and O'Brien, C.P. (2003). A functional polymorphism of the mu-opioid receptor gene is associated with naltrexone response in alcohol-dependent patients. Neuropsychopharmacology 28 , 1546-1552.

Petrakis, I. L., O’Malley, S., Rounsaville, B., Poling, J., McHugh-Strong, C., and Krystal, J. H. (2004). Naltrexone augmentation of neuroleptic treatment in alcohol abusing patients with schizophrenia. Psychopharmacology (Berl.) 172, 291-297.

Pettinati, H. M., Oslin, D. W., Kampman, K. M., Dundon, W. D., Xie, H., Gallis, T. L., Dackis, C. A., and O'Brien, C. P. (2010). A double-blind, placebo-controlled trial combining sertraline and naltrexone for treating co-occurring depression and alcohol dependence. Am. J. Psychiatry. 167, 668-675.

Pettinati,H.M.,O’Brien, C.P., Rabinowitz, A. R., Wortman, S. P., Oslin, D. W., Kampman, K. M., and Dackis, C. A. (2006). The status of naltrexone in the treatment of alcohol dependence: specific effects on heavy drinking. J. Clin. Psychopharmacol. 26, 610-625.

Ray, L. A., and Hutchison, K. E. (2007). Effects of naltrexone on alcohol sensitivity and genetic moderators of medication response: a double-blind placebo-controlled study. Arch. Gen. Psychiatry 64, 1069-1077.

Ray, L. A., Mackillop, J., Leggio, L., Morgan, M., and Hutchison, K. E. (2009). Effects of naltrexone on cortisol levels in heavy drinkers. Pharmacol. Biochem. Behav. 91, 489-494.

Rubio, G., Manzanares, J., Lopez-Munoz, F., Alamo, C., Ponce, G., JimenezArriero, M. A., and Palomo, T. (2002). Naltrexone improves outcome of a controlled drinking program. J. Subst. Abuse Treat. 23, 361-366.

Schluger, J. H., Ho, A., Borg, L., Porter, M., Maniar, S., Gunduz, M., Perret, G., King, A., and Kreek, M. J. (1998). Nalmefene causes greater hypothalamic-pituitary-adrenal axis activation than naloxone in normal volunteers: implications for the treatment of alcoholism. Alcohol. Clin. Exp. Res. 22, 1430-1436.

Swift, R. M., Whelihan, W., Kuznetsov, O., Buongiorno, G., and Hsuing, $\mathrm{H}$. (1994). Naltrexone-induced alterations in human ethanol intoxication. Am. J. Psychiatry 151, 1463-1467.

Tidey, J. W., Monti, P. M., Rohsenow, D. J., Gwaltney, C. J., Miranda, R., Jr., McGeary, J. E., MacKillop, J., Swift, R. M., Abrams, D. B., Shiffman, S., and Paty, J. A. (2008). Moderators of naltrexone's effects on drinking, urge, and alcohol effects in non-treatmentseeking heavy drinkers in the natural environment. Alcohol. Clin. Exp. Res. 32, 58-66.

Tonigan, J. S., Miller, W. R., and Brown, J. M. (1997). The reliability of Form 90: an instrument for assessing alcohol treatment outcome. J. Stud. Alcohol 58, 358-364.

Volpicelli, J. R., Alterman, A. I., Hayashida, M., and O'Brien, C. P. (1992). Naltrexone in the treatment of alcohol dependence. Arch. Gen. Psychiatry 49, 876-880.

Volpicelli, J. R., Watson, N. T., King, A. C., Sherman, C. E., and O'Brien, C. P. (1995). Effect of naltrexone on alcohol "high" in alcoholics. Am. J. Psychiatry 152, 613-615.

Witkiewitz, K. (2008). Lapses following alcohol treatment: modeling the falls from the wagon. J. Stud. Alcohol Drugs 69, 594-604.

Zhou, X. H., and Liang, H. (2006). Semiparametric single-index two-part regression models. Comput. Stat. Data Anal. 50, 1378-1390.

Zweben, A., Pettinati, H. M., Weiss, R. D., Youngblood, M., Cox, C. E., Mattson, M. E., Gorroochurn, P., and Ciraulo, D. (2008). Relationship between medication adherence and treatment outcomes: the COMBINE study. Alcohol Clin. Exp. Res. 32, 1661-1669.

Conflict of Interest Statement: The authors declare that the research was conducted in the absence of any commercial or financial relationships that could be construed as a potential conflict of interest.

Received: 27 February 2010; paper pending published: 13 April 2010; accepted: 21 July 2010; published online: 12 October 2010. Citation: Ray LA, Krull JL and Leggio L (2010) The effects of naltrexone among alcohol non-abstainers: results from the COMBINE Study. Front. Psychiatry 1:26. doi: 10.3389/fpsyt.2010.00026

This article was submitted to Frontiers in Addictive Disorders, a specialty of Frontiers in Psychiatry.

Copyright (c) 2010 Ray, Krull and Leggio. This is an open-access article subject to an exclusive license agreement between the authors and the Frontiers Research Foundation, which permits unrestricted use, distribution, and reproduction in any medium, provided the original authors and source are credited. 